\title{
The afferent pupillary defect in acute optic neuritis
}

\author{
C. J . K . E L L I S \\ From the Department of Medical Ophthalmology, St Thomas' Hospital, London
}

SUMMARY Twenty-two patients with acute optic neuritis were studied by the techniques of infrared pupillometry and visual evoked responses (VER) to pattern reversal. A relative afferent pupillary defect was found in all cases and the magnitude of this defect was found to be related to the amplitude, but not to the latency, of the VER. During follow-up the afferent defect was found to remain persistently abnormal while other methods of clinical evaluation could not demonstrate abnormality reliably. The amplitude of the VER also remained low.

Pupillary reactions have been recorded for centuries and have been used as an indication of pathology in the anterior visual pathways. Early interpretations of pupillary abnormalities were inaccurate because of misunderstanding of basic visual physiology. However, with increasing awareness of the true nature of vision, pupillary reactions were widely used as a guide to visual prognosis after cataract couching.

Saint-Yves (1742) described in detail a patient blind in one eye in whom the pupil dilated on closing the other eye and contracted when it was opened again. He also related the degree of impairment of vision to the reduction in amplitude of the pupil constriction saying "if the iris has one quarter of its movement, we judge that quarter of the sight remains." Similar findings indicating that pupillary reactions show characteristic abnormalities in association with conditions that affect vision have been reported by other authors (Gerold, 1846; Hirschberg, 1884). Kestenbaum (1946) in describing the alternate cover test named these findings after Marcus Gunn (1904) who had reported his frequent use of pupillary signs in diagnosis. Thus when Levatin (1959) introduced the swinging light test into clinical practice he was not describing any previously unrecognised pupillary abnormality, but rather was facilitating the assessment of pupillary function by comparing the response of the two eyes when alternately stimulated with light of the same intensity. Levatin described two main abnormalities. On the side of a partial optic nerve lesion the direct light reaction was reduced in amplitude and under con-

Address for reprint requests: Dr C. J. K. Ellis, Department of Medical Ophthalmology, St Thomas' Hospital, London SE1 7EH.

Accepted 10 April 1979 tinuing light stimulation there was a more marked pupillary redilatation (or "escape") than in the other eye. Levatin stressed that the presence of an abnormality of this test did not imply that the other eye was normal, but only that the two eyes were not affected equally. Thus the affected eye is said to show a relative afferent defect.

It was not until the advent of infrared pupillometry (Lowenstein and Friedman, 1942) that detailed analysis of pupillary function in lesions of the afferent pupillary pathways became possible. This technique, by using infrared illumination, allows pupillary reflexes to be recorded continuously and in darkness. Lowenstein (1954) found that in optic neuritis the pupillary responses in an eye with an afferent defect were reduced in amplitude, poorly sustained, and had a prolonged latency. He named these responses "low-intensity" reactions because of their similarity to reflexes elicited by low intensity light stimulation in normal eyes. Thompson (1966) described similar abnormalities in patients with optic nerve compression. Fison et al. (1979) quantitated the relative afferent defect and showed a close inverse relation between visual acuity and the magnitude of the relative afferent defect.

Abnormalities of the occipital pattern evoked response in acute optic neuritis have been studied in detail (Halliday et al., 1972). The characteristic prolonged latency appears to be caused, at least in part, by the presence of demyelination in the optic nerve (McDonald and Sears, 1970; McDonald, 1977a).

There has been no study correlating pupillary responses with the visual evoked responses in acute optic neuritis. In this paper I report the results of such a study of 22 patients investigated by infra- 
red pupillometry, visual evoked responses (VER) to pattern reversal, and clinical assessment. The patients were studied several times during and after the acute phase of their illness. The pupillary abnormalities, their relation to the VER, and their use as a means of assessment in optic neuritis are discussed.

\section{Subjects and methods}

Nineteen healthy subjects were investigated by infrared pupillometry. They were aged between 18 and 48 years, and 12 were female.

Visual evoked responses were performed on 20 healthy subjects between 20 and 35 years of age. Fifteen of these subjects were female. Refractive errors were corrected by spectacles.

Twenty-two patients with unilateral acute optic neuritis were studied. The age range of the patients was 16 to 48 years, and 16 were female. The patients were followed up for a mean of five months (range 1-8 months) after the onset of visual symptoms. The diagnosis of acute optic neuritis was made on clinical grounds (McDonald, 1977b) and supported by the subsequent clinical course. Other causes of optic neuropathy were excluded by appropriate investigations in each case.

During follow-up seven patients showed clinical and VER evidence of a recurrent attack of optic neuritis. Two patients were lost to follow-up after the first examination. Four patients had evidence of disseminated lesions on presentation.

\section{PUPILLOMETRY}

A Whittaker series 1800 infrared television pupillometer was used in this study. The pupillometer analyser system measured the maximum vertical pupillary diameter and this was recorded continuously on a paper recorder and on magnetic tape for computer analysis. The characteristics of the television system imposed a limit on resolution of timed events of $20 \mathrm{~ms}$ and on pupillary diameter of approximately $0.03 \mathrm{~mm}$.

A $100 \mathrm{~ms}$ white light stimulus, focused to a $2.0 \mathrm{~mm}$ beam at the midpupillary point was delivered every eight seconds from an angle $7 \circ 31^{\prime}$ lateral to visual axis. An electronic shutter gave the stimulus almost square wave characteristics. Movements of the shutter were also recorded on the magnetic tape for latency analysis. Six light intensities were employed by filtering the two Sylvania concentrated arc lamps with neutral density filters. The intensity of the two stimulus lamps was measured regularly with a photometer to enst re equal stimulus intensity in the two eyes.
All subjects were dark-adapted in red goggles for 30 minutes before pupillometry. Recordings were made in darkness with the patient's head supported comfortably while fixating a distant object by means of a mirror system. Between six and 10 stimuli were delivered first to the affected eye, at each level of light intensity. A pause between increments of stimulus intensity allowed dark adaptation to be maintained. Care was taken to ensure that the non-stimulated eye was kept in darkness.

The output from the pupillometer was recorded on a Yasec CD110 FM cassette data taperecorder and replayed into a Varian V72 digital computer with compensation for variation in tape speed by utilising a reference input channel. The computer was programmed to average the direct pupillary responses at each level of stimulus intensity and to give accurate numerical values for reflex amplitude, latency from stimulus to onset of pupillary constriction, and maximum rate of pupillary constriction. Details of the computer programme will be published elsewhere.

\section{VISUAL EVOKED RESPONSES}

The visual evoked responses were recorded to pattern reversal stimuli between a midoccipital electrode $50 \mathrm{~mm}$ above the inion and a midfrontal reference electrode.

Electrodes were $9 \mathrm{~mm}$ silver chlorided plates and were attached to the scalp with collodion. Electrode resistance was maintained below $1.5 \mathrm{k} \Omega$.

A slide of a black and white checkerboard pattern was back-projected onto a translucent screen. The pattern was displaced through one square width every $500 \mathrm{~ms}$, and each pattern reversal was completed in $6 \mathrm{~ms}$.

The luminance of the black squares was $20 \mathrm{~cd} /$ $\mathrm{m}^{2}$ and of the white squares $215 \mathrm{~cd} / \mathrm{m}^{2}$. The overall luminance of the pattern did not change. The pattern subtended $30^{\circ}$ of field and the individual squares $44^{\prime}$.

Routinely, 128 pattern reversals were averaged in two successive recordings and these results averaged to give values for 256 reversals. The VER was amplified and averaged by a Medelec DAV6 averager (band width of amplifier $0.16 \mathrm{~Hz}-$ $0.8 \mathrm{~Hz}$ ) and was recorded on photosensitive paper. The subjects viewed the pattern from one metre and recordings were made from each eye separately. Refractive errors were corrected with spectacles. Patients with reduced visual acuity and difficulty fixating the centre of the pattern were helped by a centrally placed cross or more peripherally placed marker that lay within their visual field. 
Measurements of latency were made to the peak of the major positive potential, and the amplitude was measured from the preceding negative peak.

\section{CLINICAL ASSESSMENT}

The pupils were assessed clinically by the swinging light test. Visual acuity was measured to distant and near objects using Snellen charts and standard test types.

Colour vision was assessed with H-R-R pseudoisochromatic plates under standard lighting conditions. Visual fields were tested on the Friedmann Central Field Analyser and on the Goldmann perimeter. Subtle defects demonstrated on these tests were confirmed on the two metre tangent screen. Macular threshold was recorded from the Friedmann Analyser. The irides of each patient were examined with a Haag-Streit 900 slit lamp to exclude local pathology.

Where possible patients were examined at approximately weekly intervals during the acute phase of the illness and then at longer intervals once visual acuity had returned to normal. All tests were performed at one recording session. The relationships between stimulus intensity, reflex amplitude, latency, and maximum rate of pupillary constriction were expressed mathematically by second order polynomials using standard techniques: $95 \%$ confidence limits were calculated in order to deñne the limits of the normal range.

\section{Results}

\section{PUPILLOMETRY}

\section{Light reflex amplitude}

In all control subjects the amplitude of the change in pupil diameter during the direct light reflex increased with increasing stimulus intensity. This was not a linear relationship at the higher stimulus intensities as shown by the normal range in Fig. 1 . There was a wide variation of reflex amplitude among the control subjects indicated by the $95 \%$ confidence limits. All but two of the 104 values from the control subjects lay within these limits.

In any individual subject at any given level of stimulus intensity, the difference in amplitude of the direct light reflex from the two eyes was generally small. However, there was a wider variation in this interocular difference at the lower stimulus intensities than at the three highest intensities, at which levels the difference was consistently small. Thus for each subject a single numerical value of interocular difference was given by the mean of the values at the three highest stimulus intensities. These values from the 19 control subjects are given in Fig. 2.

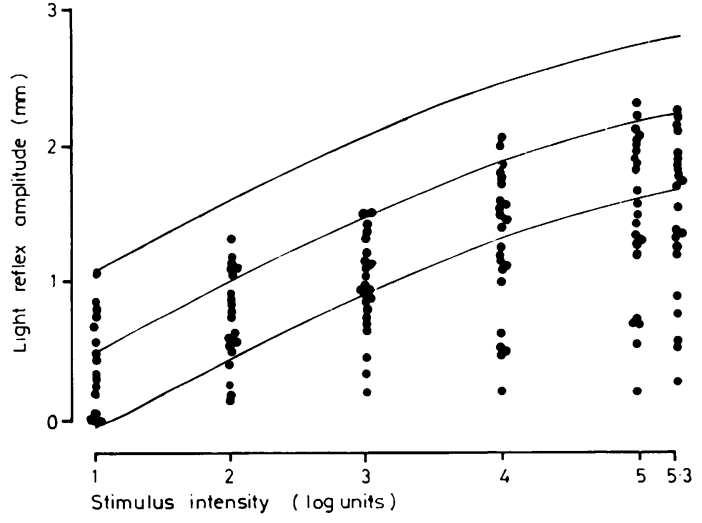

Fig. 1 Relationship between light reflex amplitude and stimulus intensity. The lines indicate the mean and the $95 \%$ confidence limits from the control subjects determined in this and all subsequent figures by second order polynomials. The black dots indicate the values from the affected eye of the 22 patients at the same levels of stimulus intensity on their first examination.

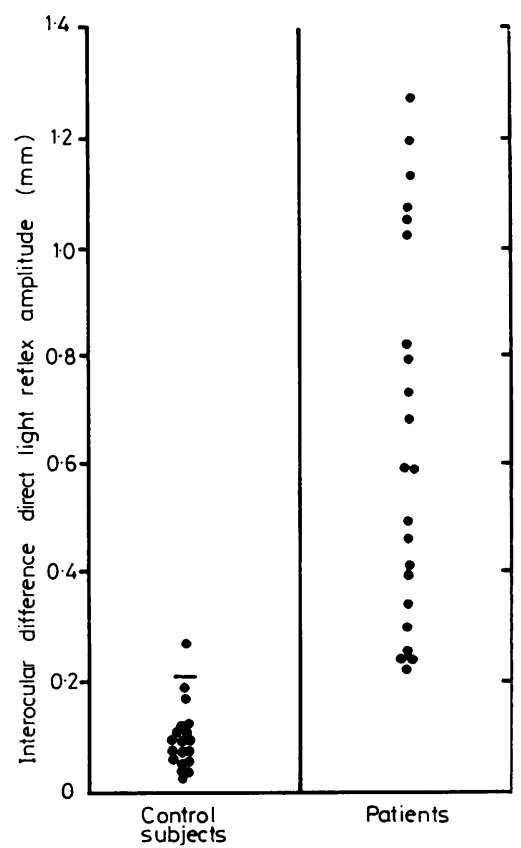

Fig. 2 Interocular difference in amplitude of the direct light reflex. These values are determined by taking the mean interocular difference at the three highest stimulus intensities. The bar indicates the mean $+2 S D$. Values from the patients relate to their first examination. 
The mean interocular difference was $0.09 \mathrm{~mm}$ (SD $0.06 \mathrm{~mm}$ ), and the upper limit of the normal range was defined as the mean $+2 \mathrm{SD}$, namely $0.21 \mathrm{~mm}$. One subject lay outside this normal range.

The light reflex amplitude was reduced in all 22 patients. This reduction could be identified either by comparison with the control range or by comparison with the reflex amplitude from the asymptomatic eye. Figure 1 shows the values from the affected eye of the patients. The number of values that lay outside the normal range varied with the level of stimulus intensity, being $50 \%$ of all values at the three highest levels. At the lower stimulus intensities fewer pupils can be shown to have a small reflex amplitude. The most severely affected patients with visual acuity of $6 / 60$ or less showed a reflex amplitude of less than $1.50 \mathrm{~mm}$ in the affected eye at the highest stimulus intensity. Patients with less reduction in visual acuity all showed values in excess of $1.50 \mathrm{~mm}$. However, the most intense stimulus available was not sufficient to elicit a maximal response.

When light reflex amplitude in the two eyes was compared, the interocular difference was found to increase with increasing stimulus intensity. A value for this interocular difference at the three highest stimulus intensities was calculated as for the control subjects. Figure 2 shows the values from the 22 patients on their first examination. All lay outside the normal range and varied from the severely affected patient with an interocular difference of $1.28 \mathrm{~mm}$ down to $0.23 \mathrm{~mm}$. This value was used as an expression of the magnitude of the relative afferent pupillary defect.

The magnitude of the relative afferent defect assessed on the first examination in each patient was found to correlate with the visual acuity at that time (Fig. 3). The afferent defects of magnitude in excess of about $0.8 \mathrm{~mm}$ were all associated with visual acuity of $6 / 60$ or less. The smaller afferent defects were associated with correspondingly less impairment of visual acuity.

\section{Latency}

The latency from stimulus to onset of response in control subjects was found to decrease with increasing stimulus intensity. Figure 4 shows the line of best fit of this relationship and the $95 \%$ confidence limits. Three of the 106 values lay outside these confidence limits. The minimum latency recorded from the control subjects was $220 \mathrm{~ms}$.

The latency was also analysed in relation to the corresponding light reflex amplitude. Figure 5 shows that latency decreases with increasing light reflex amplitude: again $95 \%$ confidence limits are

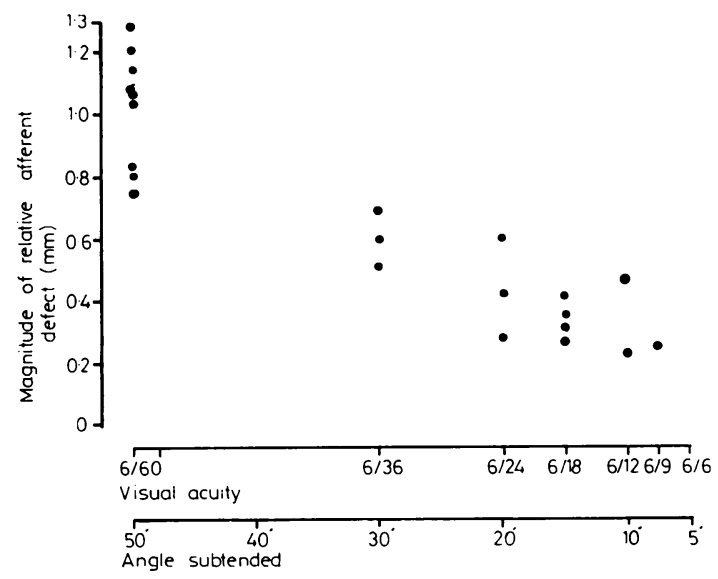

Fig. 3 Relationship between the magnitude of the relative afferent defect and visual acuity in the affected eye of the 22 patients on their first examination. Acuity of $6 / 60$ also includes all patients with vision worse than $6 / 60$.

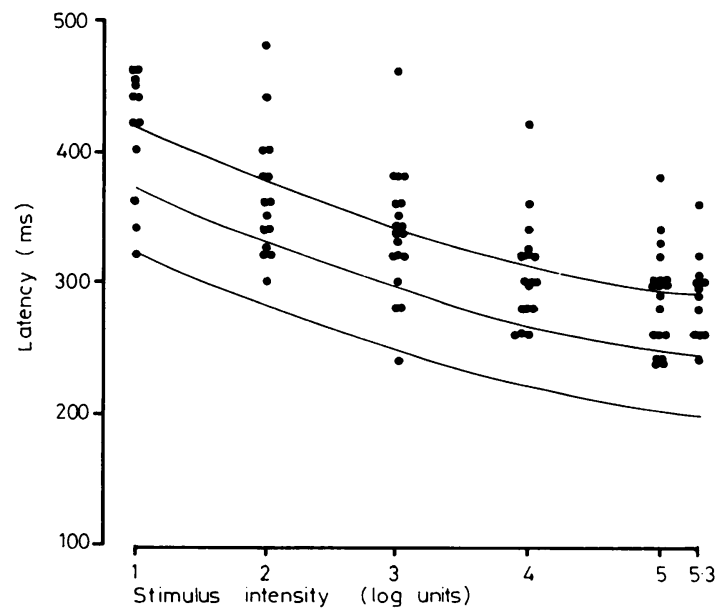

Fig. 4 Relationship between latency and stimulus intensity. The lines indicate the mean and the $95 \%$ confidence limits from the control subjects. The black dots indicate the values from the affected eye of the patients at the same levels of stimulus intensity on their first examination.

shown. Two of the 106 values lay outside this range.

The latency of the pupillary responses in the affected eyes of patients was prolonged in most cases. This abnormality was less obvious than the associated reduction in light reflex amplitude, possibly because of the low resolution of the pupillometer and the difficulties of defining exactly the onset of the pupillary constriction. However, Fig. 


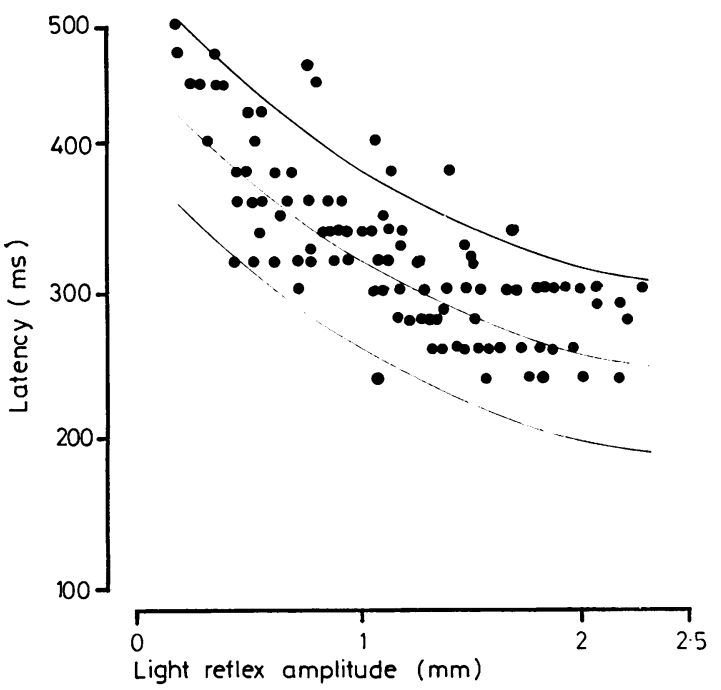

Fig. 5 Relationship between latency and amplitude of the light reflex. The lines indicate the mean and the $95 \%$ confidence limits from the control subjects. The black dots indicate the values from the affected eye of the patients on their first examination.

4 shows a number of affected eyes to lie outside the normal range of latency at each level of stimulus intensity. The longest latency recorded was $480 \mathrm{~ms}$, and upper limit of the normal range was $420 \mathrm{~ms}$ at the lowest stimulus intensity. When latency was plotted against light reflex amplitude (Fig. 5) all but eight of the values from the patients lay within the normal range, indicating that although the latency was abnormal with respect to stimulus intensity, it was normal with respect to its corresponding light reflex amplitude.

\section{Maximum rate of pupillary constriction}

The maximum rate of pupillary constriction in control subjects was found to increase with increasing stimulus intensity. Figure 6 shows the mean and $95 \%$ confidence limits of this relationship. Four of the 113 values from the control subjects lay outside these confidence limits.

Figure 7 shows the maximum rate of pupillary constriction plotted against the corresponding light reflex amplitude. This shows the constriction rate increasing with increasing light reflex amplitude. None of the 113 values from the control subjects lay outside the $95 \%$ confidence limits shown.

The maximum rate of pupillary constriction in the patients is shown in Fig. 6 plotted against stimulus intensity. Although many of the values lie outside the normal range at the higher stimulus

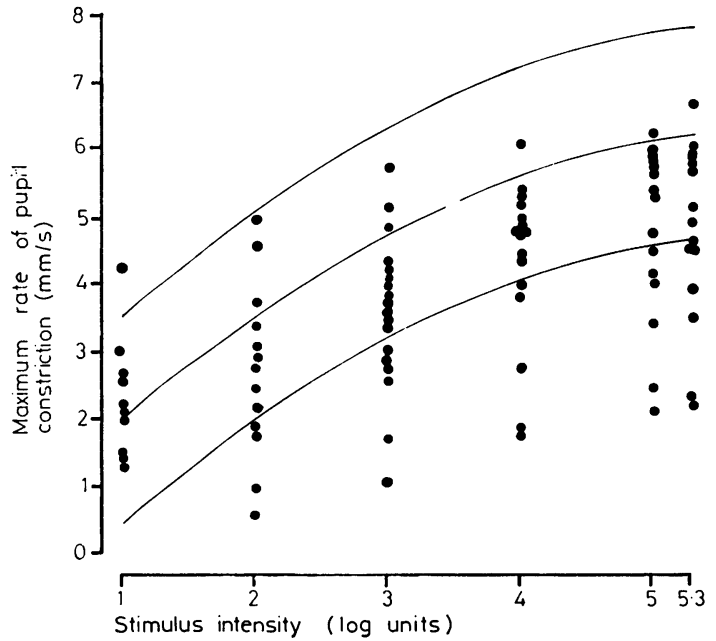

Fig. 6 Relationship between maximum rate of pupillary constriction and stimulus intensity. The lines indicate the mean and $95 \%$ confidence limits from the control subjects. The dots indicate the values from the affected eye of the patients at the same level of stimulus intensity on their first examination.

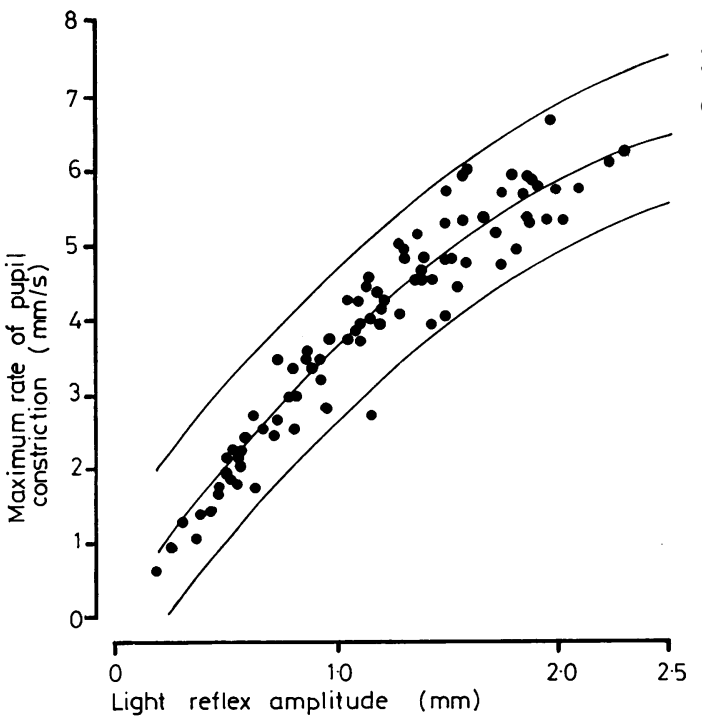

Fig. 7 Relationship between maximum rate of pupillary constriction and light reflex amplitude. The lines indicate the mean and $95 \%$ confidence limits from the control subjects. The dots indicate the values from the affected eye of the patients at their first examination. 
intensities, the majority are inside and can be shown to be abnormal only by comparison with the other eye.

When plotted against light reflex amplitude all except one of these values lay within the normal range (Fig. 7). Thus when a pupil was found to constrict slowly, that rate of constriction was only abnormal with respect to stimulus intensity and not to reflex amplitude.

\section{VISUAL EVOKED RESPONSES (VER) \\ Amplitude}

The amplitude of the major positive potential was measured from the preceding negative peak. The mean peak amplitude from the 40 eyes of the 20 control subjects was $11.0 \mu \mathrm{V}$ (SD $2.6 \mu \mathrm{V})$. There was a consistently small interocular difference in amplitude in the control subjects. This difference was expressed as a percentage of the larger amplitude, and the mean was found to be $4.3 \%$ (SD $3.1 \%$ ). The upper limit of the normal range was defined as the mean $+2 \mathrm{SD}$, namely $10.5 \%$. None of the control subjects lay outside this range.

The amplitude of the major positive peak was reduced when evoked from all the affected eyes of patients. Visual acuity of $6 / 60$ or worse was associated with abolition of any recognisable positive peak. The degree of reduction of the VER amplitude relative to the other eye was found to correlate with the magnitude of the relative afferent defect such that the larger the afferent defect, the greater the reduction in the VER amplitude

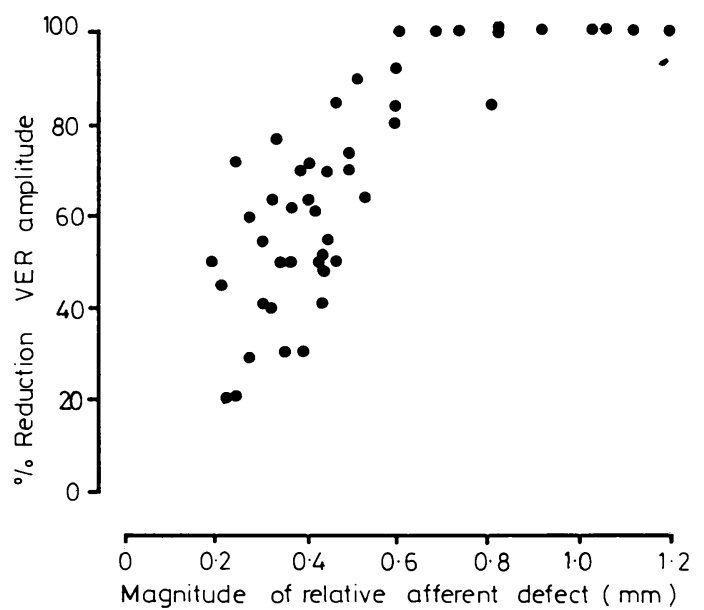

Fig. 8 Relationship between VER amplitude and magnitude of the relative afferent defect. VER reduction of $100 \%$ indicates abolition of the response. The values are taken from the patients at presentation and during follow-up.
(Fig. 8). A reduction of $100 \%$ in VER amplitude denotes abolition of any recognisable positive potential, and this was seen with afferent defects of magnitude greater than about $0.6 \mathrm{~mm}$. However, it was a significant finding that in patients with abolition of the VER and visual acuity of worse than $6 / 60$, pupillary responses were still present. The values in Fig. 8 are taken both from the first visit of the patients and during follow-up.

\section{Latency}

The latency was measured to the peak of the major positive wave. The mean from the 40 control eyes was $104.0 \mathrm{~ms}$ (SD $3.5 \mathrm{~ms}$ ). The upper limit of normal was defined as the mean +3 SD (115 ms). This was the criterion used by Asselman et al. (1975). None of the control eyes gave a latency outside this range.

The latency to the peak of the major positive potential was prolonged from all affected eyes. Five of the 22 patients had prolonged VER latencies from their asymptomatic eye, at the first examination. Four of these had clinical evidence of further lesions in the nervous system. The interocular difference in latency, in the patients in whom there was a detectable positive peak from the affected eye, was not related to the magnitude of the afferent defect.

\section{CLINICAL ASSESSMENT}

On presentation all patients had clinically detectable relative afferent pupillary defects in the affected eye. The magnitude of the defect varied in relation to visual acuity (Fig. 3). All patients showed a central scotoma on Goldmann and Friedmann field testing. The macular threshold correlated with visual acuity at presentation. Vision of less than 6/36 was associated with no recordable macular threshold on the Friedmann analyser. Fourteen of the 22 patients had disc swelling at presentation. The presence of disc swelling did not correlate with severity as assessed by any other of the tests performed. Colour vision was affected in all cases, both red-green and blueycllow defects being associated with the severe cases, and only red-green defects being associated with the mildly affected cases.

\section{FOLLOW-UP STUDIES}

During follow-up, seven of the 22 patients developed some evidence, either clinically or on VER examination, of involvement of the other optic nerve. Assessment of the relative afferent defect in these cases was unreliable. T\%O patients did not attend for follow-up. Most information was gained 


\begin{tabular}{|c|c|c|c|c|c|c|c|}
\hline \multirow{2}{*}{$\begin{array}{l}\text { Time atter } \\
\text { onset of } \\
\text { symptoms }\end{array}$} & \multicolumn{2}{|c|}{ Visual evoked response } & \multirow{2}{*}{$\begin{array}{l}\text { Size of } \\
\text { afferent } \\
\text { pupillary } \\
\text { defect }(\mathrm{mm})\end{array}$} & \multirow{2}{*}{$\begin{array}{l}\text { Visual } \\
\text { acuity } \\
\text { (left) }\end{array}$} & \multirow{2}{*}{$\begin{array}{l}\text { Macular } \\
\text { threshold } \\
\text { (left) }\end{array}$} & \multirow{2}{*}{$\begin{array}{l}\text { Visual } \\
\text { tield } \\
\text { (left) }\end{array}$} & \multirow{2}{*}{$\begin{array}{l}\text { Colour } \\
\text { vision } \\
\text { (left) }\end{array}$} \\
\hline & Right eye & Left eye & & & & & \\
\hline 8 days & & & 0.83 & $3 / 60$ & 0 & $\begin{array}{l}\text { Central } \\
\text { scotoma }\end{array}$ & $\begin{array}{l}\text { Plates } \\
\text { not } \\
\text { seen }\end{array}$ \\
\hline 16 days & & & 0.53 & $6 / 9$ & $1 \cdot 2$ & $\begin{array}{l}\text { Central } \\
\text { scotoma }\end{array}$ & $\begin{array}{l}\text { Severe } \\
\text { blue-yellow } \\
\text { and red- } \\
\text { green defect } \\
\end{array}$ \\
\hline 1 month & & & $0 \cdot 37$ & $6 / 5$ & $2 \cdot 4$ & $\begin{array}{l}\text { Fibre } \\
\text { bundle } \\
\text { detect }\end{array}$ & $\begin{array}{l}\text { Mild } \\
\text { red-green } \\
\text { defect }\end{array}$ \\
\hline 6 weeks & & & 0.45 & $6 / 5$ & $2 \cdot 4$ & $\begin{array}{l}\text { Fibre } \\
\text { bundle } \\
\text { defect }\end{array}$ & $\begin{array}{l}\text { Mild } \\
\text { red-green } \\
\text { defect }\end{array}$ \\
\hline 9 weeks & & & 0.39 & $6 / 5$ & $2 \cdot 6$ & $\begin{array}{l}\text { Fibre } \\
\text { bundle } \\
\text { defect }\end{array}$ & $\begin{array}{l}\text { Mild } \\
\text { red-green } \\
\text { defect }\end{array}$ \\
\hline 3 months & & & 0.36 & $6 / 5$ & $2 \cdot 4$ & $\begin{array}{l}\text { Fibre } \\
\text { bundle } \\
\text { defect }\end{array}$ & $\begin{array}{l}\text { Plate } 3 \\
\text { missed }\end{array}$ \\
\hline 5 morths & & & $0 \cdot 40$ & $6 / 5$ & $2 \cdot 4$ & $\begin{array}{l}\text { Fibre } \\
\text { bundle } \\
\text { defect }\end{array}$ & $\begin{array}{l}\text { Plate } 3 \\
\text { missed }\end{array}$ \\
\hline
\end{tabular}

Fig. 9 Example of typical results during follow-up. Patient TO'R aged 36 years. Left optic neuritis. Results during five month follow-up. Colour vision was measured with $H-R-R$ pseudoisochromatic plates. Shows persistent abnormality of VER, pupil reaction, and subtle defects in visual fields and colour vision. Positive potentials are indicated by an upward deflection.

from the remaining 13 cases in whom an unchanging VER latency from the asymptomatic eye testified to the reliability of its use as a control.

The results from these 13 cases were similar and were typified by patient TO'R (Fig. 9). Two phases could be identified during follow-up. An initial recovery phase, which lasted until visual acuity returned to normal, was followed by a static phase in which no change in clinical state was observed. This static phase persisted for the length of followup of this study.

During the recovery phase visual acuity improved in association with an increase in VER amplitude, decrease in the magnitude of the relative afferent defect, reduction in scotoma size, decrease in macular threshold, reduction in the severity of the colour defect, and resolution of optic disc oedema.

At the end of the recovery phase visual acuity was normal in all 13 cases. Colour testing showed persistent mild red-green defects in five patients. Macular threshold remained abnormal in two cases. Visual fields tested on the Goldmann per- imeter showed a persistent abnormality in seven of the 13 cases. These abnormalities consisted of constriction of the field to a small test object, mild relative central or paracentral scotomata, or multiple arcuate defects compatible with retinal nerve fibre atrophy. These field defects were subtle and were only detectable consistently on successive testing in the most cooperative and alert patients.

A relative afferent pupillary defect was present in each of these 13 patients throughout the length of follow-up. The magnitude of this defect did not alter significantly after the reduction in magnitude seen during the recovery phase was complete. The greater the magnitude of the defect the easier was its detection by the swinging light test.

The persistent afferent defect was associated with a persistent reduction in VER amplitude relative to the other eye. The degree of this VER reduction was related to the magnitude of the relative afferent defect (Fig. 8).

In the seven cases with subsequent involvement of the other optic nerve, the magnitude of the relative afferent defect was decreased, abolished or, 
in one case, reversed. However, the relationship between the percentage reduction of VER amplitude and the magnitude of the relative afferent defect was undisturbed in these cases.

Two of the patients developed unequivocal optic disc pallor during follow-up.

In none of the 13 unilateral cases did the latency of the VER in the affected eye change during follow-up.

\section{RELATION OF PUPILLOMETRY TO THE SWINGING} LIGHT TEST

The swinging light test was performed by at least one other independent observer ignorant of the condition of the patient. It was found that relative afferent defects of magnitude in excess of $0.8 \mathrm{~mm}$ showed little or no detectable initial pupil constriction as the light fell onto the affected eye, but only rapid dilatation. Afferent defects of this magnitude were seen only in the initial, acute phase when the patient had other obvious clinical deficit. As the magnitude of the afferent defect decreased it was found that abnormalities were still detected readily if asymmetry of the amplitude of the initial pupillary constriction and subsequent pupillary escape were assessed. On this basis even the smallest significant afferent defect was detectable by the swinging light test.

\section{Discussion}

Results of this study have shown that pupillary abnormalities are a constant feature of acute optic neuritis. There was a wide physiological range of all parameters studied in the control subjects, and some affected eyes could only be shown to be abnormal by comparison with the asymptomatic eye - that is, they only showed a relative afferent defect. However, $50 \%$ of the affected eyes lay below the $95 \%$ confidence limits of light reflex amplitude at the higher stimulus intensities and thus showed an "absolute" afferent defect. This method of definition may thus be used to detect pupillary abnormality even in bilateral disease.

It is well recognised that, in any individual, variation in amplitude of the pupillary light reactions may occur under constant experimental conditions. This variation is thought to be the result of fluctuation in supranuclear inhibition of the Edinger-Westphal nucleus (Lowenstein et al., 1963).

The pupillary responses to light in an affected eye were of smaller reflex amplitude, longer latency, and slower maximum constriction velocity than in the response from the other eye at the same level of stimulus intensity. However, if re- flexes of equal amplitude in both the affected and asymptomatic eye were compared, the latency and maximum constriction velocity did not differ significantly and the only abnormality was that more intense light stimulation was required to elicit such a reflex in the affected eye. This finding implies that the afferent defect seen in optic neuritis is related to an apparently decreased stimulus intensity in the affected eye. Thus Lowenstein's description of these reflexes as "low intensity reactions" would seem entirely appropriate.

When the pupils are examined by the swinging light test two parameters of pupillary function are assessed. These are the amplitude of the initial pupillary constriction when the light falls on the eye and the pupillary redilatation, or escape, seen under continuing light stimulation. In optic neuritis reduction in the amplitude of the initial constriction and increase in pupillary escape occur together in the affected eye and constitute what is termed the relative afferent defect or Marcus Gunn sign. This study has shown that small differences in the amplitude of the initial constriction are significant and that the swinging light test provides a sensitive means of assessment of asymmetric involvement of the optic nerves.

In order to correlate pupillary abnormality with the visual evoked response and with clinical findings it has been necessary to quantify the relative afferent defect. The usual method is to reduce stimulus intensity in the normal eye with neutral density filters until the reflex amplitude in the two eyes is similar and to express the magnitude of the relative afferent defect as the value of the log units of filter required. In this study it has been shown that in the control subjects a reflex of any given amplitude has a latency and maximum constriction velocity that lie within statistically defined limits. In the patient's affected eye this fundamental relation between reflex amplitude, latency, and maximum constriction velocity was not disturbed, and values for latency and constriction velocity lay within the normal range when plotted against reflex amplitude (see Figs. 5 and 7). Therefore any one of the measured parameters of pupillary function could be used to represent the magnitude of the relative afferent defect. In this study reflex amplitude was used as it is most easily observed in clinical pupillary assessment. The differences between the reflex amplitudes from the two eyes at the three highest stimulus intensities were averaged to give a single numerical value in millimetres that represented the magnitude of the relative afferent defect. Lowenstein et al. (1964) found that in normal subjects latency did not vary with reflex amplitude 
but rather was related to stimulus intensity, and suggested that latency was, therefore, the most reliable parameter of the low intensity reaction to light. The present study using averaged pupillary responses, did not confirm this and found latency to vary with both reflex amplitude and stimulus intensity.

The visual evoked response (VER) to pattern reversal has become established as a reliable and sensitive means of detecting abnormalities in optic nerve conduction in optic neuritis (Halliday et al., 1972). In this study the commonly employed midline occipital response was measured. It is an obvious course to attempt to relate VER and pupillary latencies. However, there are difficulties in this approach. The pupillary latency is long, the minimum value in this study was $220 \mathrm{~ms}$. This is due primarily to the delay in initiating iris smooth muscle contraction. Loewenfeld (1966) found that in the pigeon-with a striated muscle sphincter-a minimum latency of around $60 \mathrm{~ms}$ could be recorded. She also found that direct electrical stimulation of the ciliary ganglion in cats-with a smooth muscle iris sphincter-resulted in a minimum latency no shorter than $180-200 \mathrm{~ms}$. It has been demonstrated repeatedly that pupillary latency decreases with increasing stimulus intensity (Alpern et al., 1963; Lowenstein et al., 1964), and in this study a range of 220 to $480 \mathrm{~ms}$ was recorded. This variability makes comparison of VER and pupillary latency difficult, and this difficulty is compounded by the resolution of the pupillometer being low in relation to that of the VER.

That the delay in the latency of the VER is not related to the magnitude of the afferent defect is suggested by two of my findings. The difference between the VER latencies from the two eyes was not related to the magnitude of the relative afferent defect. Further, during the recovery phase while the magnitude of the pupillary defect was decreasing, there was no corresponding decrease in the VER latency in that eye.

The VER amplitude from the normal controls was variable. However, the interocular difference in amplitude showed a good correlation with the magnitude of the afferent defect such that large afferent defects were associated with a greater relative reduction of VER amplitude and the most marked afferent defects with abolition of the VER. This relation implies that from the presence of a relative afferent pupillary defect may be inferred a reduction in VER amplitude in that eye. No reliable information regarding VER latency is given by pupillary examination.

Any discussion of the relation between VER and pupillometry must acknowledge one particular field of ignorance. The identity of the pupillomotor afferent nerve fibres in the optic nerve, chiasm, and tract is not known. It is now widely accepted that at the retinal level there is no distinction between pupillary and visual rods and cones (Lowenstein and Loewenfeld, 1969). However, the argument has never been resolved satisfactorily as to whether these afferent fibres are separate from ganglion cell onwards or whether the pupillary afferent fibres are collaterals of the visual afferent fibres. This study has shown a degree of concordance between pupillary and visual deficit in optic neuritis which suggests that, even if the two groups of fibres are separate, they are affected equally by the demyelinating process.

Halliday and McDonald (1977) have explained symptoms and signs in optic neuritis in relation to reduction in amplitude rather than prolongation of latency of the VER. They have attributed the recovery during the acute phase to resolution of nerve swelling and oedema with gradual reduction in the number of blocked fibres. The present results suggest that this may also be the explanation of the conduction disturbance underlying the afferent pupillary defect. Large afferent defects are seen with the more reduced VER amplitude implying a larger number of optic nerve fibres in which conduction is blocked and a consequently reduced synchronous afferent pupillary volley.

Halliday et al. (1973) also found that visual acuity and VER amplitude returned to normal together. In that study normal VER amplitude was defined in absolute terms. In the present study normal VER amplitude has been defined in relative terms, and on this basis none of the patients showed a normal amplitude during follow-up. This persistently reduced VER amplitude was associated with a persistent relative afferent defect in all patients. Although some of these patients also showed subtle visual field defects and mild abnormalities of colour vision, the pupillary abnormality was the only consistent, objective, clinical sign of the previous episode of optic neuritis. It is important to stress that during the recovery phase there is some reduction in magnitude of the afferent defect and consequently the defects seen during follow-up are less obvious than those in the acute phase. To facilitate the clinical detection of these subtle defects, Thompson (1976) has suggested that the sensitivity of the swinging light test be increased by performing it in a dark room with a bright torch so as to increase the pupillary excursions. The patient should fix a distant object in order to avoid the miosis of a near reaction and fluctuating fixation. The light should be switched from eye to eye every three to five seconds, and 
any asymmetry of the amplitude of the intial pupillary constriction or of the degree of pupillary escape should be observed. The timing of the swing may be adjusted to accentuate asymmetries in pupillary escape, but both eyes should be stimulated for the same length of time to avoid unequal bleaching of the retinae.

I am indebted to $\mathrm{Mr} \mathrm{P}$. Bourne of the Rayne Institute, St Thomas' Hospital who devised the computer programme. I would also like to thank Dr S. E. Smith of the Department of Pharmacology, St Thomas's Hospital Medical School, Dr R. W. Ross Russell of the Department of Neurology, St Thomas' Hospital, Dr Hisako Ikeda of the Rayne Institute, St Thomas' Hospital, and Professor W. I. McDonald of the Institute of Neurology for their help in devising the project and their comments on the manuscript, and Miss J. Lace for typing the manuscript. This work was undertaken during tenure of the position of Research Fellow sponsored by the Prevention of Blindness Research Fund.

\section{References}

Alpern, M., McCready, D. W., and Barr, L. (1963). The dependence of the photopupil response on flash duration and intensity. Journal of General Physiology, 47, 265-278.

Asselman, P., Chadwick, D. W., and Marsden, C. D. (1975). Visual evoked responses in the diagnosis and management of patients suspected of multiple sclerosis. Brain, 98, 261-282.

Fison, P. N., Garlick, D. J., and Smith, S. E. (1979). Assessment of unilateral afferent pupillary defects by pupillography. British Journal of Ophthalmology, 63, 195-199.

Gerold, H. (1846). Die Lehre vom schwarzen Staar und dessen Heilung, p. 30. Rubach: Magdeburg.

Gunn, R. M. (1904). Retrobulbar neuritis. Lancet, 4. 412.

Halliday, A. M., and McDonald, W. I. (1977). Pathophysiology of demyelinating disease. British Medical Bulletin, 33, 21-27.

Halliday, A. M., McDonald, W. I., and Mushin, J. (1972). Delayed visual evoked responses in optic neuritis. Lancet, 1, 982-985.
Halliday, A. M., McDonald, W. I., and Mushin, J. (1973). Delayed pattern-evoked responses in optic neuritis in relation to visual acuity. Transactions of the Ophthalmological Society of the United Kingdom, 93, 315-324.

Hirschberg, J. von (1884). Neuritis Retrobulbaris. Zentralblatt fur Praktische A ugenheilkunde, 8, 185.

Kestenbaum, A. (1946). Clinical Methods of Neuroophthalmological Examination, pp. 282-291. Grune and Stratton: New York.

Levatin, P. (1959). Pupillary escape in disease of the retina or optic nerve. Archives of Ophthalmology, 62, 768-779.

Loewenfeld, I. (1966). Recent Developments in Vision Research. National Research Council Publication, no. 1272, pp. 17-105. Edited by M. A. Whitcomb. Washington.

Lowenstein, O. (1954). Clinical pupillary symptoms in lesions of the optic nerve, optic chiasm, optic tract. Archives of Ophthalmology, 52, 385-403.

Lowenstein, O., and Friedman, E. D. (1942). The present state of pupillography: its method and diagnostic significance. Archives of Ophthalmology, 27, 969-993.

Lowenstein, O., and Loewenfeld, I. (1969). In The Eye, pp. 255-337. Edited by Hugh Davson. Academic Press: New York.

Lowenstein, O., Feinberg, R., and Loewenfeld, I. (1963). Pupillary movements associated with acute and chronic fatigue. Investigative Ophthalmology, 2, 138-157.

Lowenstein, O., Kawabata, H., and Loewenfeld, I. (1964). The pupil as indicator of retinal activity. American Journal of Ophthalmology, 57, 569-596.

McDonald, W. I., and Sears, T. A. (1970). The effects of experimental demyelination on conduction in the central nervous system. Brain, 93, 583-598.

McDonald, W. I. (1977a). In Virual Evcked Potentials in Man: New Developments, pp. 427-437. Edited by J. E. Desmedt. Clarendon Press: Oxford.

McDonald, W. I. (1977b). Acute optic neuritis. British Journal of Hospital Medicine, 18, 42-48.

Saint-Yves, C. de (1742). Un nouveau traité des maladies des yeux, p. 291. Pierre-Augustin le Mercier: Paris.

Thompson, H. S. (1966). Afferent pupillary defects. American Journal of Ophthalmology, 65, 860-873.

Thompson, H. S. (1976). Pupillary signs in the diagnosis of optic nerve disease. Transactions of the Ophthalmological Society of the United Kingdom, 96, 377-381. 